\title{
Allozyme divergence and phylogenetic relationships among species of tephritid flies
}

\author{
ANNA R. MALACRIDA*, CARMELA R. GUGLIELMINO $\dagger$, PATRIZIA D'ADAMO \\ CRISTINA TORTI, FULVIA MARINONI \& GIULIANO GASPERIS \\ Dipartimento di Biologia Animale, Laboratorio di Zoologia, Università di Pavia, Piazza Botta 9, 1-27100, Pavia, \\ $\nmid$ Dipartimento di Genetica e Microbiologia, Università di Pavia, via Abbiategrasso 207, 1-27100, Pavia, $\ddagger / s t i t u t o ~ d i$ \\ Genetica Biochimica ed Evoluzionistica de/ CNR, via Abbiategrasso 207, 1-27100, Pavia and §/stituto di Zoologia, \\ Università di Sassari, Via Muroni 25, 1-07100 Sassari, Italy
}

\begin{abstract}
Multilocus enzyme electrophoresis data from 24 orthologous loci (212 alleles) were used to infer the genetic similarities between 11 Tephritidae pest species from the Ceratitis, Trirhithrum, Capparimyia, Bactrocera, Anastrepha and Rhagoletis genera. Within some of the considered species, different degrees of genetic variability were demonstrated, which appear to be related to zoogeography and to the biological traits peculiar to each species. Nei (1978) and Cavalli-Sforza \& Edwards (1967) genetic distances were used to express the genetic divergence and to infer phylogenetic relationships among the species. The UPGMA clustering algorithm and the optimality criteria of Fitch \& Margoliash (1967), with ( $\mathrm{KITSCH}$ ) and without (FITCH) the tree constrained to have contemporary tips, were used. All the methods indicate the same clusters of species. One cluster is composed of Ceratitis capitata, Trirhithrum coffeae and Capparimyia savastanoi, another is composed of Rhagoletis cerasi, Bactrocera dorsalis and Bactrocera oleae. A further loose cluster is comprised of Ceratitis rosa and Anastrepha spp. The congruence between electrophoretic phylogeny and morphological classification is discussed. Our analysis also elucidated cases, within the Ceratitis and Bactrocera genera, of interest from the evolutionary point of view, where allozyme dendrograms do not correlate well with morphological taxonomic relationships.
\end{abstract}

Keywords: cluster analysis, genetic distances, genetic variability, multilocus enzyme electrophoresis, Tephritidae.

\section{Introduction}

The family Tephritidae, the true fruit flies, is one of the most economically important dipteran families. Most of the species are pests of soft fruits, including many commercial fruits. Because of their economical importance, detailed research has been carried out on their physiology, ecology, genetics and evolution (for comprehensive reviews see Robinson \& Hooper, 1989; White \& Elson-Harris, 1992). Fruit flies are represented in all world regions, but the major pest genera, Ceratitis, Bactrocera, Rhagoletis and Anastrepha, each have limited natural distributions. However, mankind has played an important part in altering the distribution of some of the more polyphagous species, as well as certain oligophagous species, by extending the range of their plant hosts.

\footnotetext{
${ }^{*}$ Correspondence.
}

The question of why only a few species have become major pests has been approached by studies on zoogeography (Maddison \& Bartlett, 1989) and on analysis of the life history strategies that each species has evolved (Fletcher, 1989). The degree of phenotypic plasticity that each species has retained has been related to the unpredictability of its habitat, in terms of resource availability in time and space. The majority of these flies belong to the $r$-strategists; however, most species are at the low end of the spectrum. Polyphagous multivoltine tropical and subtropical species such as Ceratitis capitata, Bactrocera dorsalis and Anastrepha ludens have typical $r$-characteristics, whereas oligophagous and stenophagous/monophagous species such as Bactrocera oleae, Anastrepha fraterculus and Anastrepha suspensa have life history characteristics that exhibit a mixture of $r$ - and $K$-traits.

Studies on distribution and host relationships have evidenced a prolific speciation resulting in a large 
number of species $(>4000)$ and in a morphological overlap among the higher taxa (White \& ElsonHarris, 1992). In addition, a large number of sibling and cryptic species are known in Rhagoletis (Bush, 1966, 1969), and the Anastrepha fraterculus and Bactrocera dorsalis complexes (White \& ElsonHarris, 1992). In this context, Rhagoletis flies ( $R$. pomonella species complex) have been at the centre of a discussion on sympatric speciation (Bush, 1966, 1969; Feder et al., 1988, 1990). Electrophoretic studies of genetic differentiation have provided a powerful tool for the analysis of sympatric speciation and phylogeny in Rhagoletis (Berlocher \& Bush, 1982; Berlocher et al., 1993), for resolving species complexes in the $A$. fraterculus group (Malavasi \& Morgante, 1983; Steck, 1991) and in population genetic analysis in C. capitata (Gasperi et al., 1991; Malacrida et al., 1992; Baruffi et al., 1995). All of these studies suggest the great potential of genetic approaches for biogeographical and phylogenetic analysis of Tephritidae flies.

Despite years of taxonomic work, no satisfactory classification and phylogeny exist for these flies (White, 1989). The most common problems are synonymy, homonymy and the establishment of supra- specific groups based on questionable characters. This situation may be the consequence of the large size of the group, the regional nature of most taxonomic work and the fact that it has been hard to find sound taxonomic characters. An immunological (Kitto, 1983) and, more recently, a molecular approach (Han \& McPheron, 1994) have been proposed to help the creation of a phylogenetically based classification for the Tephritidae.

In this paper we have attempted to elucidate the relationships among species of the related genera Ceratitis, Thirhithrum, Capparimyia, Bactrocera, Anastrepha and Rhagoletis using the multilocus enzyme electrophoretic approach (MLEE). The outcome of variability estimates and genetic similarities among the species are discussed in relation to biological characteristics, zoogeography and to the current taxonomic position of each of the considered species.

\section{Materials and methods}

\section{Species samples}

A total of 23 samples from 11 tephritid species were analysed for electrophoretic variation (Table 1). Each sample was composed of 30-50 flies.

Of the 11 species, five, i.e. Ceratitis capitata, Ceratitis rosa, Trirhithrum coffeae, Capparimyia savastanoi and Bactrocera oleae, are represented by samples collected from the wild. Samples of the species $C$. capitata, $C$. rosa and $T$. coffeae are from sympatric populations and were collected together on the same host (coffee berries) in their putative original area (Kenya; White \& Elson-Harris, 1992). Wild samples from C. rosa were also collected in Réunion Island.

The remaining six species listed in Table 1 were from laboratory colonies.

\section{Electrophoretic procedures}

We performed electrophoretic analysis using cellulose acetate gels (Cellogel) adopting the procedures described in Gasperi et al. (1991).

The following 24 orthologous enzyme loci $(212$ alleles) were analysed in each single fly of the 23 samples: Pgm, Hk $, \mathrm{Hk}_{2}, \mathrm{Pgi}, \mathrm{Pgk}, \mathrm{Zw}, \mathrm{Pgm}, \alpha \mathrm{Gpdh}$, $A_{\text {con }}$, Acon $_{2}, I d h, F h, M d h_{1}, M d h_{2}, A k_{1}, A k_{2}, A d h_{2}$, Aox, Got,$G_{1}$, Gpt, Had, Me, Mpi. All the considered loci produced consistently interpretable banding patterns in all species studied and the determination of isozyme locus homologies was unambigous.

For each of these biochemical loci, the electrophoretic banding patterns of $C$. capitata were used as a standard because electrophoretic variation in this species is well documented (Gasperi et al., 1991; Malacrida et al., 1992; Baruffi et al., 1995).

\section{Data analysis}

For each species sample we calculated standard measurements of polymorphism and heterogeneity: $P$ (proportion of polymorphic loci), $A$ (average number of alleles per locus) and $H$ (average proportion of heterozygous individuals).

The PHYLIP computer package (Felsenstein, 1993) was used for the cluster analysis of the 23 samples. We calculated the genetic distance between each pair of samples using both Nei (1978) and CavalliSforza \& Edwards (1967) genetic distances. Two different methods of tree construction were employed. The first utilized the unweighted pair group method using an arithmetic average (UPGMA) clustering algorithm; the other used the optimality criteria of Fitch and Margoliash (1967), first with (KITSCH), and then without (FITCH) the tree constrained to have contemporary tips (Felsenstein, 1984).

We also applied the bootstrap test (Efron, 1982) for assessing the robustness of each node in the tree topology. For this purpose we analysed 100 replicates of bootstrap resampling of the original data 
matrix and constructed a consensus tree from the 100 bootstrapped trees obtained.

\section{Results}

\section{Parameters of genetic variability}

In Table 2 we show the levels of genetic variability estimated in the wild samples of $C$. capitata, C. rosa,
T. coffeae, $C$. savastanoi and $B$. oleae species considering all 24 loci.

Among the three sympatric samples from the native range of $C$. capitata, $C$. rosa and $T$. coffeae we observed different levels of variability. Ceratitis capitata is the most polymorphic $(\bar{H}=0.138)$ whereas $T$. coffeae appears to be the least variable $(\bar{H}=0.060)$. Comparable low levels of variability were found for

Table 1 Origin and date of collection of the samples from the considered Tephritidae species

\begin{tabular}{|c|c|c|}
\hline Species & Origin & Date of collection \\
\hline \multicolumn{3}{|c|}{ Ceratitis capitata } \\
\hline 1 sample* & Kenya (Kabete, Machacos, Ruiru) & 1984-92 \\
\hline \multicolumn{3}{|l|}{ Ceratitis rosa } \\
\hline 4 samples & Kenya (Kabete, Machacos, Ruiru) & $1984-88$ \\
\hline 2 samples & Réunion Island & 1989 \\
\hline \multicolumn{3}{|c|}{ Trirhithrum coffeae } \\
\hline 2 samples & Kenya (Kabete, Machacos, Ruiru) & 1988 \\
\hline \multicolumn{3}{|c|}{ Capparimyia savastanoi } \\
\hline 2 samples & Italy (Pantelleria Island) & $1987-88$ \\
\hline \multicolumn{3}{|c|}{ Bactrocera oleae } \\
\hline 2 samples & Italy (Liguria, Apulia) & $1990-93$ \\
\hline \multicolumn{3}{|c|}{ Bactrocera cucurbitae } \\
\hline 2 samples & $\begin{array}{l}\text { Lab. colonies from: Col. Agric., Okinawa } \\
\text { (Japan), and USDA, Honolulu (Hawaii) }\end{array}$ & $1991-92$ \\
\hline \multicolumn{3}{|c|}{ Bactrocera dorsalis } \\
\hline 1 sample & Lab. colony from USDA, Honolulu (Hawaii) & 1992 \\
\hline \multicolumn{3}{|c|}{ Anastrepha suspensa } \\
\hline 4 samples & Lab. colony from Dept. Agr. Gainesville (Florida) & $1990-93$ \\
\hline \multicolumn{3}{|c|}{ Anastrepha ludens } \\
\hline 1 sampie & Lab. colony from Tapachula (Mexico) & 1990 \\
\hline \multicolumn{3}{|c|}{ Anastrepha serpentina } \\
\hline 1 sample & Lab. colony from Tapachula (Mexico) & 1990 \\
\hline \multicolumn{3}{|c|}{ Rhagoletis cerasi } \\
\hline 1 sample & Lab. colony from Sissac (Switzerland) & 1993 \\
\hline
\end{tabular}

${ }^{*}$ Gene frequencies in this sample result from the weighted average of 11 samples from the Kenya population. We decided to group them because they appear very similar to each other when considered singly.

Table 2 Parameters of genetic variability in the wild samples of Ceratitis capitata, Ceratitis rosa, Trirhithrum coffeae, Capparimyia savastanoi and Bactrocera oleae

\begin{tabular}{lllll}
\hline Species & Origin & $\bar{A} \pm \mathrm{SD}^{*}$ & $\bar{P} \pm \mathrm{SD}^{*}$ & $\bar{H} \pm \mathrm{SD}^{*}$ \\
\hline C. capitata & Kenya & 3.300 & 0.417 & 0.138 \\
C. rosa & Kenya & $1.625 \pm 0.096$ & $0.396 \pm 0.024$ & $0.107 \pm 0.034$ \\
& Réunion & $1.450 \pm 0.071$ & $0.312 \pm 0.029$ & $0.117 \pm 0.078$ \\
T. coffeae & Kenya & $1.300 \pm 0.000$ & $0.250 \pm 0.000$ & $0.060 \pm 0.047$ \\
C. savastanoi & Italy & $1.300 \pm 0.000$ & $0.125 \pm 0.059$ & $0.059 \pm 0.011$ \\
B. oleae & Italy & $1.550 \pm 0.071$ & $0.291 \pm 0.059$ & $0.089 \pm 0.002$ \\
\hline
\end{tabular}

${ }^{*}$ SD Standard deviation. 
the other two species, C. savastanoi $(\bar{H}=0.059)$ and B. oleae $(\bar{H}=0.089)$.

General low levels of variability (not reported in Table 2) were found in the considered laboratory strains of $B$. cucurbitae $(\bar{H}=0.061), B$. dorsalis $(\bar{H}=0.049), A$. suspensa $(\bar{H}=0.053)$ and $A$. serpentina $(\bar{H}=0.089)$; in the colonies of $A$. ludens and $R$. cerasi higher levels of variability were detected ( $\bar{H}=0.121$ and $\bar{H}=0.132$, respectively).

\section{Genetic distances}

The matrix of the interspecific Nei genetic distances (Nei, 1978) is shown in Table 3. The lowest genetic distance $(D=0.78)$ is observed between $C$. capitata and $T$. coffeae. The genetic distance observed between the two congeneric species $C$. capitata and $C$. rosa is $D=1.02$, and those observed between $C$. rosa and the Anastrepha species are of the same order of magnitude, i.e. $D=1.05$ with $A$. suspensa, $D=1.31$ with $A$. ludens and $D=0.89$ with $A$. serpentina. Within Anastrepha we observed a distance value of 0.81 between the two species ( $A$. suspensa and $A$. ludens) from the fraterculus group (Norrbom \& Kim, 1988). Slightly higher distance values separate these last two species from $A$. serpentina (serpentina group), being $D=0.83$ and $D=0.93$, respectively. Within the Bactrocera genus we observed the highest interspecific distance values: $B$. cucurbitae vs. $B$. dorsalis is 1.53 , and vs. B. oleae is 2.15 .

In Table 4 we summarize the average Nei genetic distance values between the considered genera. The lowest value is the distance between the Ceratitis and Anastrepha genera $(D=1.103)$ followed by the distance between Ceratitis and Trirhithrum $(D=1.242)$. The largest distances separate the genus Bactrocera from the Trirhithrum $(D=2.679)$, Capparmyia $(D=2.534)$ and Anastrepha $(D=2.285)$ genera.

\section{Cluster analysis}

The results of the cluster analysis are shown in Figs 1-3. UPGMA trees computed using $\mathrm{Nei}$ genetic distances and Cavalli-Sforza chord measures (Cavalli-Sforza \& Edwards, 1967) are shown in Fig. $1(a, b)$. They represent the consensus trees of 100 bootstrap resamples of the original data set. Both trees show the same topology, confirmed also by relatively high bootstrap values especially at the terminal nodes of the trees. In both trees the first splits separate two of the Bactrocera species (B. dorsalis and $B$. oleae) and Rhagoletis cerasi. The two next splits separate two groups of species: one

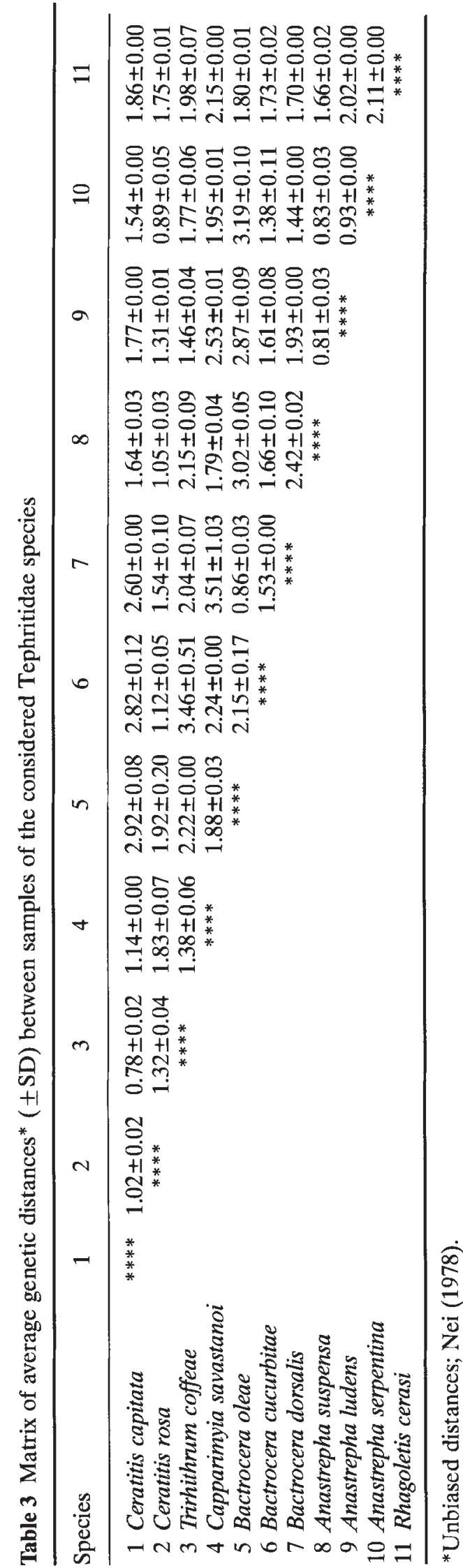


(a)

Ceratitis rosa

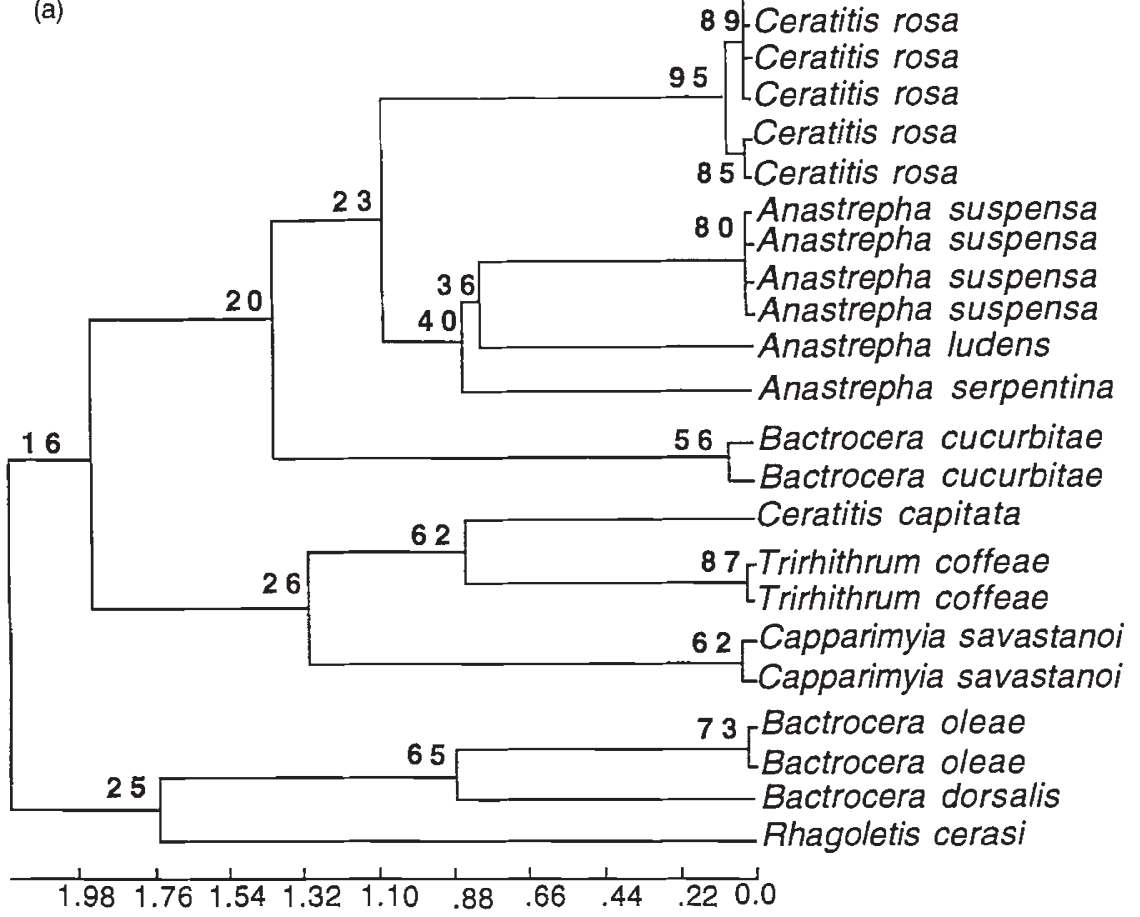

Nei Distance

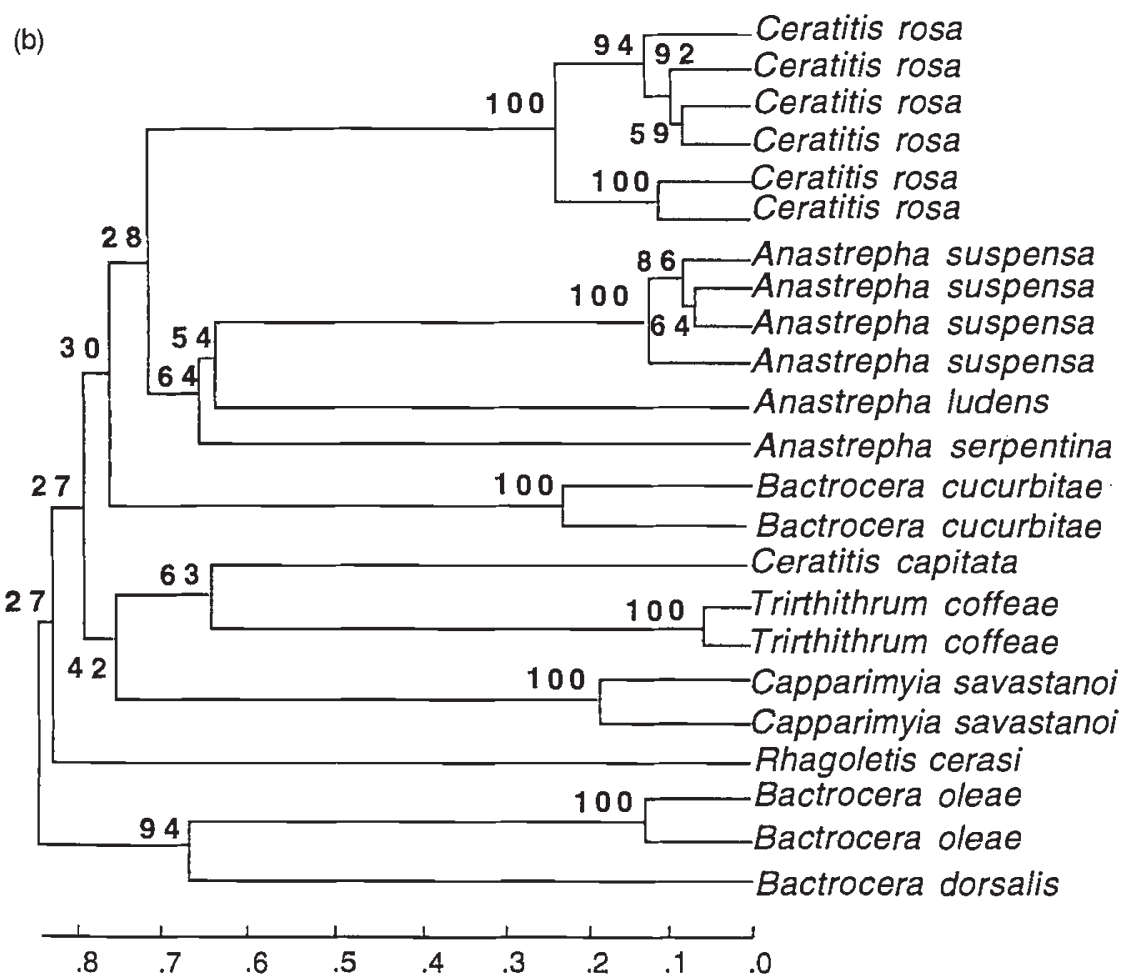

Cavalli-Sforza and Edwards Distance

Fig. 1 Tephritid relationships inferred from uPGMA dendrograms obtained from 100 bootstrap resamplings of: (a) Nei unbiased genetic distance (1978) and (b) Cavalli Sforza and Edwards (1967) chord distance. Numbers at the nodes represent the percentage of a group's occurrence in 100 bootstrap replicates. 
Table 4 Matrix of average genetic distances* ( \pm sd), between the genera Ceratitis, Trirhirithrum, Capparimyia, Bactrocera, Anastrepha, Rhagoletis

\begin{tabular}{lcccccc}
\hline & 1 & 2 & 3 & 4 & 5 & 6 \\
\hline 1. Ceratitis & $*$ & $1.242 \pm 0.207$ & $1.735 \pm 0.258$ & $1.725 \pm 0.580$ & $1.103 \pm 0.177$ & $1.772 \pm 0.040$ \\
2. Trirhithrum & & $*$ & $1.375 \pm 0.059$ & $2.679 \pm 0.740$ & $1.973 \pm 0.292$ & $1.983 \pm 0.067$ \\
3. Capparimyia & & & & $2.534 \pm 1.073$ & $1.942 \pm 0.282$ & $2.153 \pm 0.005$ \\
4. Bactrocera & & & & $2.285 \pm 0.679$ & $1.752 \pm 0.050$ \\
5. Anastrepha & & & & & $1.810 \pm 0.200$ \\
6. Rhagoletis & & & & & & $*$ \\
\hline
\end{tabular}

${ }^{*}$ Unbiased genetic distance; Nei (1978).

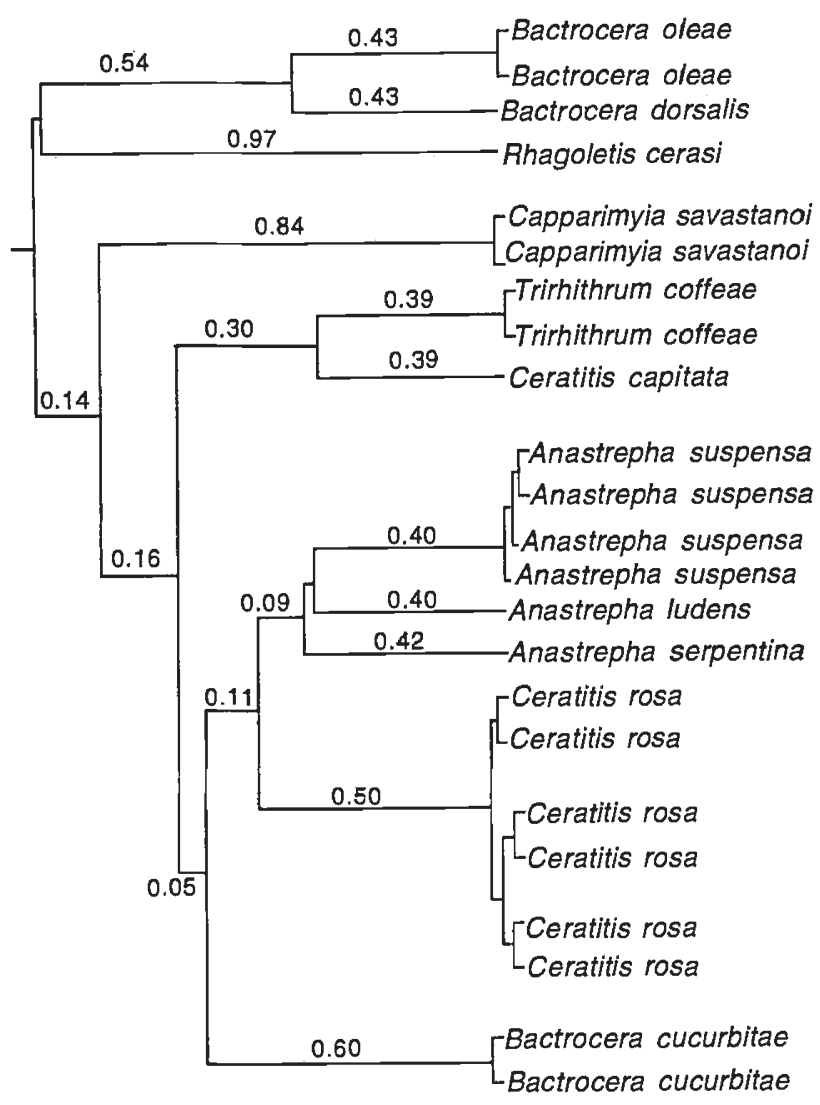

Fig. 2 Tephritid relationships inferred from KiTsCH (ultrametric) tree derived from Fitch-Margoliash optimality criteria with the assumption of equal rates of evolution (Felsenstein, 1984). The numbers represent the length of the branches (only those greater than 0.04 ).

includes $C$. rosa and the three species of Anastrepha; the other groups $T$. coffeae, $C$. capitata and $C$. savastanoi. The hypothetical relationship between species within these two clusters is suggested in general by less than a bootstrap proportion of 50 per cent; however, the affinity between $T$. coffeae, $C$. capitata and $C$. savastanoi is suggested by a higher value of repeatability, especially in the Cavalli-Sforza \& Edwards tree.

The ultrametric tree derived from Fitch-Margoliash optimality criteria (KITSCH) is shown in Fig. 2. This tree confirms the grouping pattern shown in the previous trees which were based on the same assumption of equal rates of evolution among the taxa.

The unrooted tree in Fig. 3, constructed without the constraint of a constant rate of evolution (FITCH), shows similar clustering of species; the clusters $C$. savastanoi-C. capitata-T. coffeae and $R$. cerasi-B. dorsalis $-B$. oleae are preserved; but we observe that $C$. rosa and the Anastrepha species are not accommodated in a single cluster although they separate in subsequent lineages.

\section{Discussion}

We used genetic distance to express the total genetic divergence and to infer the phylogenetic relationships among some economically important species of Tephritidae, the majority of which are subject to alternative classifications on morphological bases (Fig. 4).

We used allozyme data from 24 orthologous loci. On the basis that these loci are widely distributed over the genetic maps of some Rhagoletis species (Feder, 1989) and C. capitata (Malacrida et al., 1990), it is reasonable to assume that these loci may be considered a random, although small, sample of the genomes of the considered Tephritidae species. In addition, these loci code for a variety of enzymes with both singular and multiple physiological substrates, and for both monomeric and multimeric enzymes, which contribute differentially to overall heterozygosity (Zouros, 1976).

In a preliminary attempt to compare the genetic variation among the wild samples of the considered species, we found different levels of intraspecific 


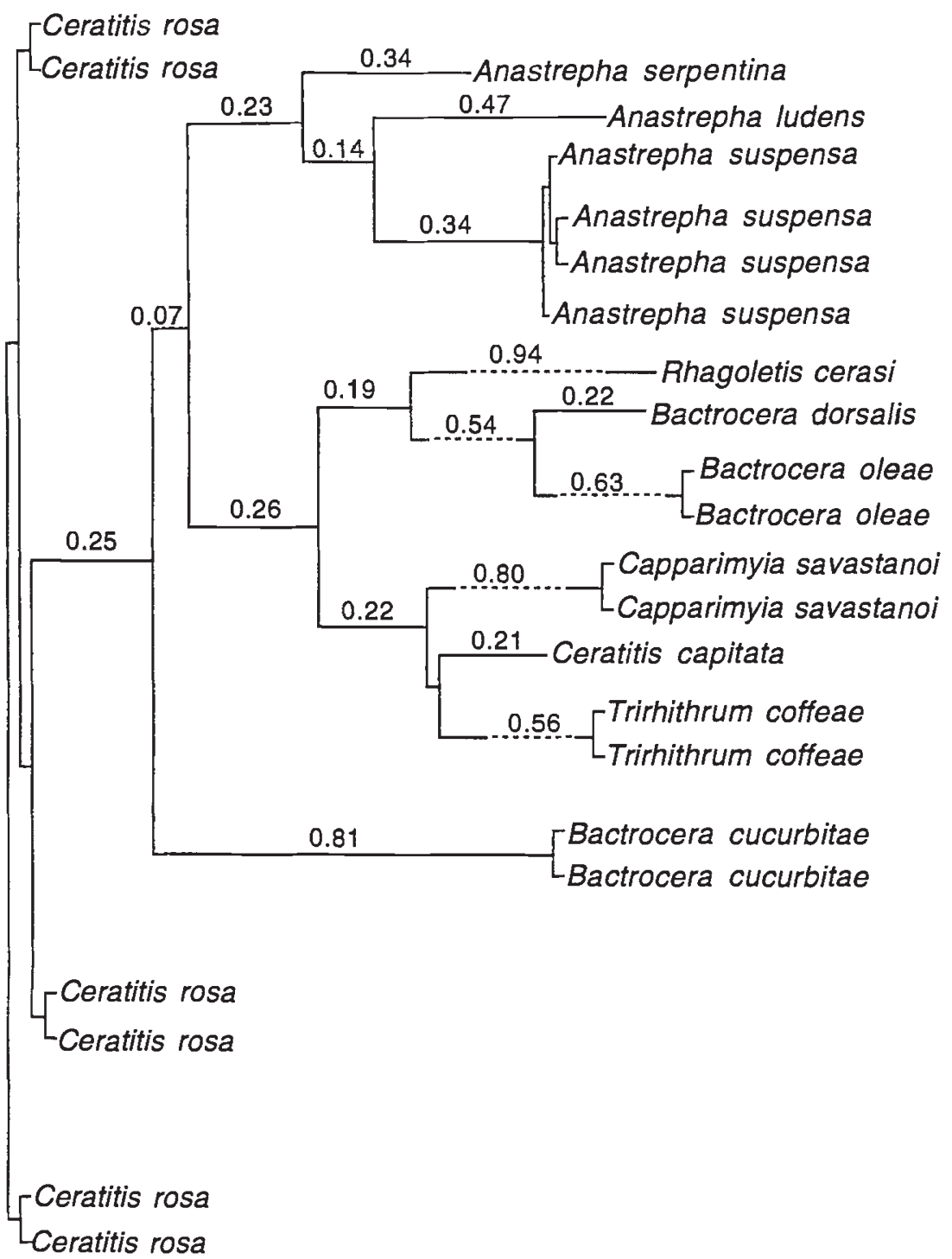

Fig. 3 FITCH unrooted tree (Felsenstein, 1984) derived from FitchMargoliash optimality criteria without the assumption of equal rates of evolution for all tip species of Tephritidae considered. The numbers represent the length of the major branches. variability. In particular, marked differences in genetic variability were found among sympatric samples of the three species $C$. capitata, $C$. rosa and $T$. coffeae collected together in one of their putative original areas (Kenya; White \& Elson-Harris, 1992). As these samples are sympatric we can exclude the possibility that the observed intraspecific variability is affected by geographical and/or climatic factors. This level of genetic variability may reflect the specific genetic plasticity and parallels the differential dispersion capacity of these three species. In fact, $C$. capitata which is polyphagous and has a cosmopolitan geographical distribution is the most polymorphic, whereas $T$. coffeae which is monophagous and is considered an endemic species of Western Africa (White \& Elson-Harris, 1992) has the lowest level of genetic variability. The intermediate level of genetic variability shown by Ceratitis rosa corresponds to the medium level of geographical diffusion of this polyphagous species. During the dispersion processes $C$. capitata loses the greatest part of its variability (Baruffi et al., 1995); its peripheral Mediterranean populations show levels of polymorphism comparable to the ones detected in Kenyan samples of $T$. coffeae. No information is available on the genetic structure or dispersion of geographical populations of $C$. rosa and $T$. coffeae.

The low level of variability detected in the wild samples of the other two species, C. savastanoi and $B$. oleae, can be related to their narrow host specialization (Nevo et al., 1984). For B. oleae high genetic similarity has been found among distant geographi- 
Tephritidae $\left\{\begin{array}{l}\text { Dacinae }\left\{\begin{array}{l}\text { Daculus oleae (Musca oleae) } \\ \text { Zeugodacus cucurbitae (Dacus cucurbitae) }\end{array}\right. \\ \text { Ceratitinae }\left\{\begin{array}{l}\text { Ceratitis capitata } \\ \text { Pterandrus rosa (Ceratitis rosa) } \\ \text { Trirhithrum coffeae (Ceratitis nigra) } \\ \text { Capparimyia savastanoi }\end{array}\right.\end{array}\right.$

Fig. 4 Morphologically based Tephritidae subfamily relationships proposed by various authors for the species considered in this study. The relationships proposed by Cogan \& Munro (1980) and Kugler \& Freidberg (1975) are summarized in (a), and those proposed by Hancock $(1984,1987)$ and White \& ElsonHarris (1992) are summarized in (b). The original designations for the species which were subject to alternate classification are given in brackets.

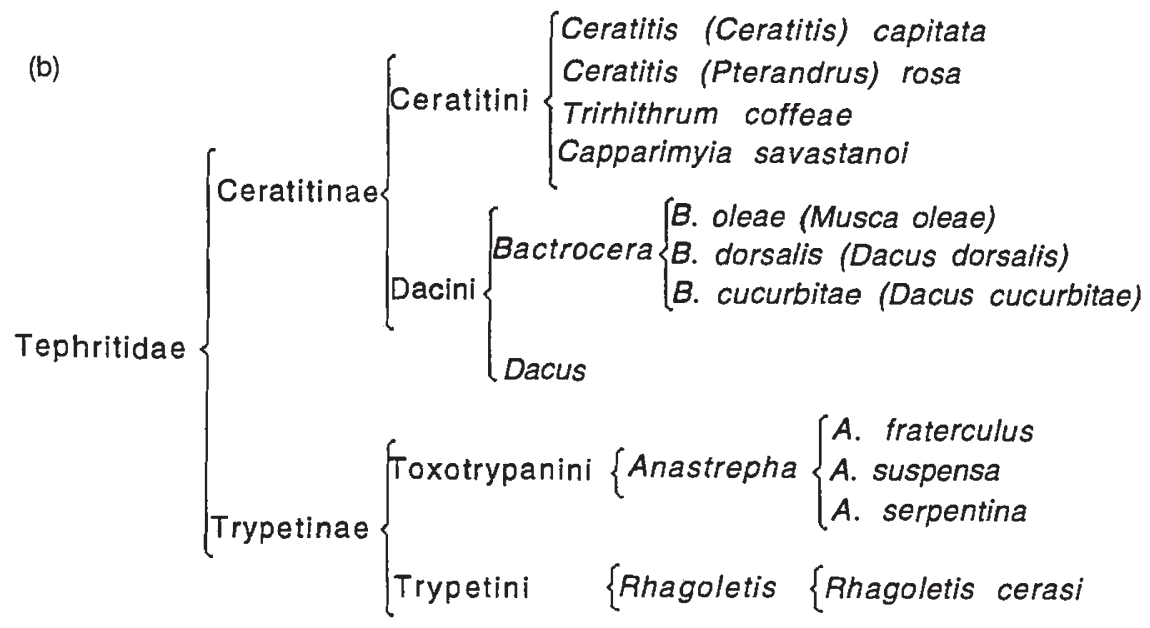

cal populations (Zouros \& Loukas, 1989) and this finding has been correlated with the insect's total dependence on the olive fruit.

The specific life history characteristics of these species may also be related to their degree of variabilty. Species such as $C$. capitata and $C$. rosa, which have the attributes of $r$-strategist species (Fletcher, 1989) are also highly polymorphic, whereas species such as $C$. savastanoi and $B$. oleae, which are considered $r-K$ strategists, are also less polymorphic.

\section{Congruence between electrophoretic trees}

In this study we produced different electrophoretic estimates of the phylogeny of Tephritidae flies, one assuming a molecular clock (UPGMA and $\mathrm{KITCH}$ trees) and one making no rate assumptions (FITCH tree). The first conclusion which can be drawn from the tree analysis is that all the topologies obtained are similar, suggesting that we cannot exclude the possibility that rates of enzyme evolution in different clades are similar. All methods indicate the presence of the same clusters of species. One cluster is composed of $T$. coffeae, $C$. capitata and $C$. savasta$n o i$, and another is composed of $R$. cerasi, $B$. dorsalis and $B$. oleae. A further loose cluster includes $C$. rosa and the Anastrepha species; affinity between them is evident in all the trees; however, only trees based on the assumption of constant evolutionary rate accommodate them under a common hypothetical ancestor.

\section{Congruence between electrophoretic phylogeny and the conventional classification}

Figure 4 shows the Tephritidae subfamily relationships based on morphological traits, proposed by various authors in recent years for the species considered in this study. Clearly, there is no generally accepted classification of the Tephritidae.

Nevertheless, there are areas of agreement between the electophoretic trees and some of the proposed classifications. The primary agreement concerns the closely conserved electrophoretic cluster: C. capitata, T. coffeae and $C$. savastanoi. That is, the demonstrated genetic affinity parallels 
the classical taxonomy in that the three species are grouped under a separate subfamily (Ceratitinae) according to Cogan \& Munro (1980) and even under a separate tribe (Ceratitini) according to White \& Elson-Harris (1992). Trirhithrum coffeae was previously included in the Ceratitis genus by the original designation of Ceratitis nigra Graham (Cogan \& Munro, 1980). The low genetic distance $(0.78)$ between $C$. capitata and $T$. coffeae is in agreement with this previous classification.

The two primary disagreements concern all the electrophoretic trees and involve the species-genus relationships. First, the two congeneric species $C$. capitata and $C$. rosa are separated, secondly, $B$. cucurbitae appears to be genetically unrelated to its congeners $B$. dorsalis and $B$. oleae. In our trees $C$. capitata is closer to $T$. coffeae than to $C$. rosa. This result may indicate how poorly external morphology reflects genetic affinity. Furthermore, $C$. rosa, like $T$. coffeae, has been assigned to various taxonomic relationships. It is regarded now (Hancock 1984, 1987) as a member of the subgenus Pterandrus Bezzi of the Ceratitis genus, whereas previously Cogan \& Munro (1980) regarded Pterandrus as a separate genus. From the morphological point of view, Ceratitis (Ceratitis) capitata and Ceratitis (Pterandrus) rosa are separated on the basis of the male secondary sexual characters, with females being inseparable at the generic level (Hancock, 1984). We can speculate that speciation between these two Ceratitis species may have been accelerated by this specific sexual differentiation (Singh, 1988). On the other hand, some caution is necessary to exclude in our study the possibility that by chance we looked at enzyme loci which remain unalterated in some widely separated lines, but were strongly selected in C. rosa.

Concerning the relationships deduced from the genetic distances among the three Anastrepha species ( $A$. serpentina, $A$. ludens, $A$. suspensa), this is an area of agreement within the infrageneric classification of Norrbom \& Kim (1988): the two fraterculus group species $A$. suspensa and $A$. ludens are more closely related to each other than to $A$. serpentina which belongs to its own subgroup.

The second open question from our electrophoretic results is the unexpected separation within the Bactrocera genus. The Bactrocera species here considered are members of the following different subgenera: B. (Daculus) oleae, B. (Zeugodacus) cucurbitae and B. (Bactrocera) dorsalis (White \& Elson-Harris, 1992). The large genetic distance estimates which separate $B$. cucurbitae from $B$. oleae $(D=2.15)$ and from $B$. dorsalis $(D=1.53)$ are in the range of those expected between different genera (Thorpe, 1982). As reported in White \& ElsonHarris (1992) B. cucurbitae, like other Zeugodacus species, has a pattern of host relationships, which differentiate this species from other Bactrocera. This species attacks the flowers rather than the fruit of the Cucurbitaceae, a trait which is more typical of Dacus than Bactrocera.

Regarding tribe-genus relationships, our electrophoretic data support the close affinities between Ceratitini species and Dacini species proposed by Hancock (1986) and Kitto (1983). White \& ElsonHarris (1992) placed these two tribes within a single subfamily of Ceratitinae.

For Rhagoletis we have considered only one sample from a single species: $R$. cerasi. In our tree this Rhagoletis sample is clustered with $B$. dorsalis and $B$. oleae. The current classification places Rhagoletis and Bactrocera in different subfamilies. However, genetic affinity between the two Bactrocera species ( $B$. oleae and $B$. dorsalis) and the primitive Rhagoletis species, i.e. $R$. cerasi, parallels a result of Han \& McPheron (1994) who recognized a close similarity between two Bactrocera species ( $B$. cucurbitae and $B$. dorsalis) and one Rhagoletis species ( $R$. striatella) based on the analysis of nuclear ribosomal DNA.

\section{Conclusion}

Several considerations emerge from our results. Individual variation is critical for the study of the systematics of closely related species, unlike higher taxonomic levels (Soto-Adames et al. 1994). As expected, electrophoretic data offer a great degree of reliability in ordering genetic similarities between closely related tephritid species. They will be useful in a reanalysis of the morphological data for a reorganization of the formal taxonomic structure of Tephritidae flies, especially at genus-species level. Moreover, our analysis demonstrated cases, within the Ceratitis and Bactrocera genera, of most interest from the evolutionary point of view, in which allozyme dendrograms do not conform well with the morphological taxonomic relationships. If certain loci can be pinpointed, an important clue to the microevolution of these species may be at hand. Finally, the different degrees of genetic variability demonstrated for the different pest species seem related to zoogeography and to biological traits which are peculiar to each species. This opens the problem of the role of genetic variability in dispersion processes of these species. 


\section{Acknowlegdements}

We are indebted to the following people for having provided the specimens studied: J.Hendrich (IAEA, Vienna, Austria), T. Mukiama (University of Nairobi, Kenya); E. Osir (ICIPE, Nairobi, Kenya); S. Quilici (IFRA, Saint-Pierre, La Réunion); D.O. Mc-Innis (USDA-ARS, Honolulu, Hawaii); P. Liedo (Tapachula, Messico); C.O. Calkins (USDA, Washington, USA). We thank Drs D. Frohlich and L. Gomulski for reading the manuscript. This research was supported by the C.N.R. (National Research Council of Italy), Special Project RAISA, Subproject No. 2, paper no. 2471. Grants from M.U.R.S.T. (National Ministry of the University and Scientific Research and Technology) (funds 40 per cent) and from IAEA (International Atomic Energy Agency, Vienna, Austria) also contributed to this work.

\section{References}

BARUfFI, L., DAMIANI, G., GUGLIElmino, C. R., BANDI, C., MAlACRIDA, A. R. AND GASPERI, G. 1995. Polymorphism within and between populations of Ceratitis capitata: comparison between RAPD and multilocus enzyme electrophoresis data. Heredity, 74, 425-437.

BERLOCHER, S. H. AND BUSH, G. L. 1982. An electrophoretic analysis of Rhagoletis (Diptera: Tephritidae) phylogeny. Syst. Zool., 31, 136-155.

BERLOCHER, S. H., McPHERON, B. A., FEDER, J. L. AND BUSH, G. L. 1993. Genetic differentiation at allozyme loci in the Rhagoletis pomonella (Diptera: Tephritidae) species complex. Ann. Entomol. Soc. Am., 86, 716-727.

BUSH, G. L. 1966. The taxonomy, cytology, and evolution of the genus Rhagoletis in North America (Diptera, Tephritidae). Bull. Mus. Comp. Zool., 134, 431-562.

BUSH, G. L. 1969. Sympatric host race formation and speciation in frugivorous flies of the genus Rhogoletis (Diptera, Tephritidae). Evolution, 23, 237-251.

CAVAlli-SFORZA, L. L. AND EDWARds, A. W. F. 1967. Phylogenetic analysis: models and estimation procedures. Evolution, 21, 550-570.

COGAN, B. H. AND MUNRO, H. K. 1980. Family Tephritidae. In: Crosskey, R. W. (ed.) Catalogue of the Diptera of the Afrotropical Region, pp. 518-554. British Museum (Natural History), London.

EFRON, B. 1982. The jackknife, the bootstrap, and other resampling plans. Conf. Board Math. Sci. Soc. Ind. Appl. Math., 38, 1-92.

FEDER, J. L. 1989. Inheritance and linkage relationships of allozymes in the apple maggot fly. J. Hered., 80, 277-283.

FEDER, J. L., CHILCOTE, C. A. AND BUSH, G. L. 1988. Genetic differentiation between sympatric host races of Rhagoletis pomonella. Nature, 336, 61-64.

FEDER, J. L., CHILCOTE, C. A. AND BUSH, G. L. 1990. Regional, local and microgeographic allele frequency variation between apple and hawthorn populations of Rhagoletis pomonella in western Michigan. Evolution, 44, 595-608.

FELSENSTEIN, J. 1984. Distance methods for inferring evolutionary trees: a justification. Evolution, 38, 16-24.

FElsenstein, J. 1985. Confidence limits on phylogenies: an approach using the bootstrap. Evolution, 39, 783-791.

FELSENSTEIN, J. 1993. PHyLIP (Phylogeny Inference Package) version 3.5c. Distributed by the author. Department of Genetics, University of Washington, Seattle.

FitCH, w. M. AND MARGOliash, E. 1967. Construction of phylogenetic trees. Science, 155, 279-284.

FLETCHER, B. s. 1989. Life history strategies of tephritid fruit flies. In: Robinson, A. S. and Hooper, G. H. S. (eds) Fruit Flies: Their Biology, Natural Enemies and Control, vol. 3B, pp. 195-208. Elsevier, Amsterdam, The Netherlands.

GASPERI, G., GUGLIELmino, C. R., MALACRIDA, A. R. AND MILANI, R. 1991. Genetic variability and gene flow in geographical populations of Ceratitis capitata (medfly). Heredity, 67, 347-356.

HAN, H. AND McPheron, B. 1994. Phylogenetic study of selected Tephritid flies (Insecta: Diptera: Tephritidae) using partial sequence of the nuclear $18 \mathrm{~S}$ ribosomal DNA. Biochem. Syst. Ecol., 22, 447-457.

HANCOCK, D. L. 1984. Ceratitinae (Diptera: Tephritidae) from Malagasy subregion. J. Entomol. Soc. South Afr., 47, 277-301.

HANCOCK, D. L. 1986. Classification of Trypetinae (Diptera: Tephritidae) with a discussion of the Afrotropical fauna. J. Entomol. Soc. South. Afr., 49, $275-305$.

HANCOCK, D. L. 1987. Notes on some African Ceratitinae (Diptera: Thephritidae), with special reference to the Zimbabwean fauna. Trans. Zim. Sci. Ass., 63, 47-57.

KITTO, G. B. 1983. An immunological approach to the phylogeny of the Tephritidae. In: Cavalloro, R. (ed.) Fruit Flies of Economic Importance, pp. 203-211. Balkema A.A., Rotterdam.

KUGleR, J. AND FEIDBERG, A. 1975. A list of the fruitflies (Diptera: Tephritidae) of Israel and nearby areas, their host plants and distribution. Israel J. Erit., 10, 51-71.

MADDISON, P. A. AND BARTLETT, B. J. 1989. A contribution towards the zoogeography of the Tephritidae. In: Robinson, A. S. and Hooper, G. H. S. (eds) Fruit Flies, Their Biology, Natural Enemies and Control, vol. 3A, pp. 27-36. Elsevier, Amsterdam, The Netherlands.

MALACRIDA, A. R., GASPERI, G., BARUFFI, L. AND MILANI, R. 1990. The contribution of formal genetic studies to the species characterization of Ceratitis capitata Wied. In: Genetic Sexing of the Mediterranean Fruit Fly, pp. 85-89. International Atomic Energy Agency Press, Vienna, Austria.

MALACRIDA, A. R., GUGliElmino, C. R., GASPERI, G., BARUFFI, L. AND MILANI, R. 1992. Spatial and temporal differentiation in colonizing populations of Ceratitis capitata. Heredity, 69, 101-111.

MAlaVASI, A. AND MORGANTE, J. s. 1983. Population genet- 
ics of Anastrepha fraterculus (Diptera, Tephritidae) in different hosts: Genetic differentiation and heterozygosity. Genetica, 60, 207-211.

NEI, M. 1978. Estimation of average heterozygosity and genetic distance from a small number of individuals. Genetics, 89, 583-590.

NEVO, E., BEILES, A. AND BEN-SHLOMO, R. 1984. The evolutionary significance of genetic diversity: ecological demographic and life history correlates. In: Mani, G. S. (ed.) Evolutionary Dynamics of Genetic Diversity. Lecture notes in Biomathematics, vol. 53, pp. 13-213. Springer-Verlag, Berlin.

NORRBOM, A. L. AND KIM, K. C. 1988. A List of the Reported Host Plants of the Species of Anastrepha (Diptera: Tephritidae). United States Department of Agriculture (APHIS 81-52), Washington.

ROBINSON A. S. AND HOOPER G. H. S. (eds). 1989. Fruit Flies: Their Biology, Natural Enemies and Control, vols $3 \mathrm{~A}$ and B. Elsevier, Amsterdam, The Netherlands.

SINGH, R. s. 1988. Genetic studies of species differences and their relevance to the problem of species formation. In: Loxdale, H. D. and Hollander, J. (eds) Electrophoretic Studies on Agricultural Pests, pp. 20-45. Oxford University Press, New York.

SOTO-ADAMES, F. N., ROBERTSON, H. M. AND BERLOCHER, S. H. 1994. Phylogenetic utility of partial DNA sequences of $G_{6} p d h$ at different taxonomic levels in hexapoda with emphasis in Diptera. Ann. Entomol. Soc. Am., 87, 723-736.

STECK, G. J. 1991. Biochemical systematics and population genetic structure of Anastrepha fraterculus and related species (Diptera: Tephritidae). Ann. Entomol. Soc. Am., $\mathbf{8 4}, 10-28$.

THORPE, J. P. 1982. The molecular clock hypothesis: biochemical evolution, genetic differentiation and systematics. Ann. Rev. Ecol. Syst., 13, 139-168.

WhiTE, I. M. 1989. The state of fruit fly taxonomy and future research priorities. In: Cavalloro, R. (ed.) Fruit Flies of Economic Importance 87, pp. 543-552. Balkema A.A., Rotterdam.

White J. M. AND ElSON-HARRIS M. (eds). 1992. Fruit Flies of Economic Significance: Their Identification and Bionomics. C.A.B. International, Wallingford, Oxfordshire.

zouros, E. 1976. Hybrid molecules and superiority of the heterozygote. Nature, 262, 227-229.

ZOUROS, E. AND LOUKAS, M. 1989. Biochemical and colonization genetics of Dacus oleae. In: Robinson, A. S. and Hooper, G. H. S. (eds) Fruit Flies: Their Biology, Natural Enemies and Control, vol. 3B, pp. 75-88. Elsevier, Amsterdam, The Netherlands. 